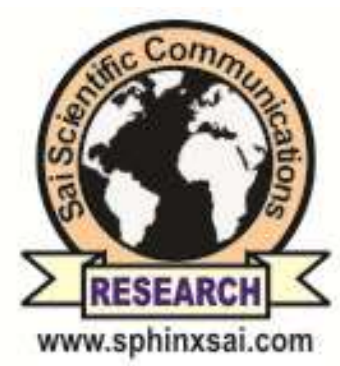

Pharmisch

International Journal of PharmTech Research CODEN (USA): IJPRIF, ISSN: 0974-4304, ISSN(Online): 2455-9563

Vol.11, No.04, pp 305-313,

2018

\title{
Application of Microencapsulated Fish oil in Instant soup mix as a source of omega-3 fatty acids
}

\author{
Asma D. Fakir ${ }^{1}$ and Jyotsna Waghmare ${ }^{1 *}$ \\ ${ }^{1}$ Department of Oils, Oleochemicals and Surfactant Technology, Institute of Chemical \\ Technology, Mumbai, India.
}

\begin{abstract}
This research study was conducted to develop an optimized formulation of instant soup mix which is enriched with omega-3 fatty acids. Sardine fish oil was used for microencapsulation by spray drying. Sardine fish oil is reach source of omega -3 fatty acids. The effect of wall material concentration and fish oil concentration on microencapsulation was studied. A Rancimat method was used to determine oxidative stability of the obtained microcapsules and Particle size analysis of the spray dried powder was done using MalvernZetasizer Nano ZS. Various batches were conducted for optimization of instant soup mix. Sensory evaluation of soup mix was done and measured overall acceptability. Oxidative stability and chemical characterization of optimized soup mix were done. This research study ensures healthy omega-3 fatty acids reach soup mix with good acceptability.
\end{abstract}

Keywords : Omega-3 fatty acids, Soup mixture and Rancimat.

\section{Introduction}

Consumer demands in the field of functionalfood production have increased considerably in recent years.Functional foods play an outstanding role in human health, increasing strength, and preventing the chronic diseases ${ }^{1}$. Fatty acids such as saturated, Monounsaturated (MUFA) and Polyunsaturated (PUFA) are beneficial for human health ${ }^{2}$. Among Polyunsaturated fatty acids, n-3 and n-6 fatty acids are important in terms of preventing many diseases. Eicosapentaenoic acid (EPA, 20:5; n-3) and docosahexaenoic acid (DHA, 22:6n3) are fall under n-3 fatty acids.

Fish are a rich source of polyunsaturated fatty acids (PUFAs), namely the n-3 and n-6 PUFAs which have a positive effect on to human health (Cleland et al; 2006).Fish has been recognized as an excellent food source for human beings and is preferred as a perfect diet due to its excellent taste and high digestibility ${ }^{3}$. For health benefits, fish oils can be consumed through either by eating fish or by taking supplements. High percentage unsaturated fatty acids containing oil are likely to oxidize by consuming atmospheric oxygen and support the degradation of oil and deteriorate the quality of oil ${ }^{4}$. The rate of deterioration of fish oil is considerably higher than that of other oils because it contains polyunsaturated fatty acids including EPA and $\mathrm{DHA}^{5}$. 
This problem of degradation of oil would possibly remedied by using microencapsulated technology as it involves shielding of the core material by a polymeric shell which reduced the interaction of the core material with surroundings ${ }^{6}$. In microencapsulation process, small quantities of solid, liquid and gaseous materials are shielded with wall material and form the microcapsules ${ }^{7}$. Spray drying process has been found effective for microencapsulation to retard the oxidation of unsaturated fatty acids ${ }^{8}$.

In this research work, microencapsulation efficiency (ME) of Sardine fish oil by spraydrying was determined and process conditions were optimized. From this process, we obtained fish oil as a powder ingredient, with improved stability against oxidationand useful to food formulation. Aninstant soup powder enriched withmicroencapsulated fish oil as a source of omega-3was formulated. Instant soup powder with omega-3 is the way to contribute to the development of food functionality which is required by current markets.

\section{Materials and methods}

Sardine Fish oil was the gifted samples obtained from Avestia Pharma, Mumbai. Hexane, Acetic acid glacial and Chloroform were provided from Rankem (Haryana, India). Iso-octane and P-Anisidine were provided from Hi-Media (Mumbai, India). All chemicals used were of analytical grade.Skim Milk powder was purchased from Hi-Media. Dry milk powder, tomato powder, pepper, salt,basil and sugar were used for soup formulation. All chemicals used were of AR grade.

\section{Emulsion Preparation}

Wall materials were separately rehydrated overnight and then gently heated at $60^{\circ} \mathrm{C}$ in a water bath to allow complete dissolution. Solutions were allowed to cool to room temperature before storing under refrigeration $\left(4^{\circ} \mathrm{C}\right)$ until emulsion preparation. Wall material was dispersed in distilled water and then rehydrated overnight at $10^{\circ} \mathrm{C}$ in a refrigerator, after which fish oil (10-30\%) was added to the mixture. The mixture is emulsified in shear homogenizer for $10 \mathrm{~min}$ at $3000 \mathrm{rpm}$ until complete dispersion of the fish oil was obtained.

\section{Spray Drying}

The slurry of carrier material, water and Fish oils (Sardine fish oil) were spray dried in a JISL, LSD-48 model mini spray drier. The pressure of the compressed air for concurrent the flow of spray was adjusted to 2 bars. The inlet and outlet temperatures were maintained to $175 \pm 5^{\circ} \mathrm{C}$ and $95 \pm 5^{\circ} \mathrm{C}$ respectively. Aspirator was adjusted to $45 \%$ and Peristaltic pump was used to feed the slurry in to nozzle at $13 \%$ efficiency. The microcapsules so prepared were collected from the collecting chamber; these powders were filled in airtight, self sealable polyethylene pouches and stored in desiccators containing calcium chloride at $25^{\circ} \mathrm{C}$ to prevent moisture absorption and lump formation until further studies.

\section{Design of wall material of microencapsulation}

The experimental design of wall material for microencapsulation is given in table 1 .

Table 1 Experimental Design of Skim milk powder as a wall material used for Microencapsulation

\begin{tabular}{|c|c|c|c|}
\hline RUN & $\begin{array}{l}\text { Aq. phase } \\
\text { content(gm) }\end{array}$ & $\begin{array}{l}\text { Solid content }(\%) \text { w.r.t } \\
\text { aq.phase }\end{array}$ & Oil conc. w.r.t. solid (\%) \\
\hline 1 & \multirow[t]{6}{*}{$-8=10$} & \multirow[t]{3}{*}{ 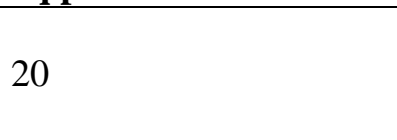 } & 10 \\
\hline 2 & & & 20 \\
\hline 3 & & & 30 \\
\hline 4 & & \multirow{3}{*}{30} & 10 \\
\hline 5 & & & 20 \\
\hline 6 & & & 30 \\
\hline 7 & \multirow[b]{3}{*}{80} & \multirow{3}{*}{20} & 10 \\
\hline 8 & & & 20 \\
\hline 9 & & & 30 \\
\hline
\end{tabular}




\begin{tabular}{|c|c|c|c|}
\hline 10 & & \multirow{3}{*}{30} & 10 \\
\hline 11 & & & 20 \\
\hline 12 & & & 30 \\
\hline 13 & \multirow{6}{*}{90} & \multirow{3}{*}{20} & 10 \\
\hline 14 & & & 20 \\
\hline 15 & & & 30 \\
\hline 16 & & \multirow{3}{*}{30} & 10 \\
\hline 17 & & & 20 \\
\hline 18 & & & 30 \\
\hline
\end{tabular}

\section{Analysis of Spray Dried Microcapsules}

The spray dried powder was analyzed for its total oil, surface oil, encapsulation and entrapment efficiencies, bulk density and powder particle size.

\section{Total Oil Determination}

Soxhlet extraction was made to determinate the oil content in obtained microcapsules. The sample material was put into an extraction thimble and then placed in a Soxhlet extractor. A condenser was installed on top of the Soxhlet extractor and fed with cooling water. The round evaporation flask was filled with $100 \mathrm{ml}$ of petroleum ether and connected to the Soxhlet extractor. The petroleum ether was heated to boiling point and run for $4.5 \mathrm{~h}$. Then the evaporation flask was put into a rotary evaporator and the petroleum ether was evaporated at $50^{\circ} \mathrm{C}$. A water vacuum pump was used to accelerate the process. Then the evaporation flask was stored under an extraction hood for $15 \mathrm{~min}$, and then the content was weighed.

\section{Surface Oil Determination}

Surface oil was determined by solvent extraction. This involves placing the encapsulated product in a flask and adding organic solvent (hexane). The flask was then shaken for several minutes. The powder was filtered from the solvent and then solvent was removed by using Rotavac unit. The residue or surface oil was determined by weighing the residue.

\section{Encapsulation Efficiency (\%)}

The encapsulation efficiency was determined using the formula listed below -

\begin{tabular}{|l|l|}
\hline Encapsulation Efficiency $(\%)=\frac{\text { Total oil Experimental loading }(\mathrm{g} / \mathrm{g}) \text { Powder }}{\text { Theoretical Loading }(\mathrm{g} / \mathrm{g}) \text { Powder }} \mathrm{X} 100$ \\
\end{tabular}

\section{Entrapment Efficiency (\%)}

The entrapment efficiency was calculated using the formula listed below -

Entrapment Efficiency $(\%)=\frac{\text { Total oil }(\mathrm{g} / \mathrm{g}) \text { Powder }- \text { Surface oil }(\mathrm{g} / \mathrm{g}) \text { Powder }}{\text { Total oil }(\mathrm{g} / \mathrm{g}) \text { Powder }} \mathrm{X} 100$

\section{Bulk Density}


Bulk density was determined by tapping method. 2 gm of powder was loosely weighed in $10 \mathrm{ml}$ graduated cylinder. Cylinder with the powder was tapped on soft surface. The final volume was recorded. Bulk density was calculated by dividing the sample weight by the volume.

\begin{tabular}{|l|} 
Bulk Density $=\quad \frac{\text { Weight of spray dried powder }}{\text { Volume of spray dried powder }}$ \\
\hline
\end{tabular}

Moisture content of microcapsule was determined based on AOAC method (AOAC, 1990) ${ }^{9}$. Two grams of finished product was weighed and then dried in an oven at $70^{\circ} \mathrm{C}$ for $24 \mathrm{hr}$.

\section{Oxidative stability of oil from microcapsules}

For these analyses, the extraction of oil from the optimizedproduct was carried out as described by Bligh and Dyer ${ }^{10} .15 \mathrm{~g}$ of microcapsules was taken for extracting oil with $15 \mathrm{~mL}$ of chloroform and $30 \mathrm{~mL}$ of methanol stirring for $2 \mathrm{~min}$ and $30 \mathrm{~s}$. A rotary evaporator used for evaporating solvent at $40^{\circ} \mathrm{C}$. The remaining residue was weighed and the oil content was calculated. The Rancimat (model 743, Metrohm) was used to determine the oxidative stability of oil extracted from microcapsules.

\section{Powder Particle Size}

Particle size analysis of the spray dried powder was done using MalvernZetasizer Nano S. It measures particle and molecule size from below a nanometer to several microns using dynamic light scattering. It measures particle size range from $0.3 \mathrm{~nm}$ to $10 \mu \mathrm{m}$.

Development of an instant soup powder enriched with microencapsulated Sardine fish oil

Total 18 batches were conducted to optimize spray drying parameters to get maximum encapsulation efficiency, total oil content, minimum surface oil. The successful batch was carry forward for the application of soup powder. Judicious blend of dry milk, tomato powder, pepper, basil, sugar and salt is made by making various permutations combinations in order to get proper taste of final product. Further optimization on nutrient dosage was performed by using various concentrations of spray dried fish oil.

Table 2 Optimization of Ingredients for different composition of fish powder with all the ingredients

\begin{tabular}{|l|l|l|l|}
\hline Ingredients & Mix-1 (\%) & Mix-2 (\%) & Mix-3 (\%) \\
\hline Dry milk powder & 50 & 45 & 40 \\
\hline Dry tomato powder & 30 & 30 & 30 \\
\hline Pepper & 2.5 & 2.5 & 2.5 \\
\hline Salt & 8 & 8 & 8 \\
\hline Basil & 2 & 2 & 2 \\
\hline Sugar & 2.5 & 2.5 & 2.5 \\
\hline $\begin{array}{l}\text { Spray dried Fish oil } \\
\text { powder }\end{array}$ & 5 & 10 & 15 \\
\hline
\end{tabular}

\section{Chemical analysis of the soup mix}

The mixes of spray dried Fish oil powder, tomato powder; dry milk powder, sugar, salt, basil and pepper were analyzed for their chemical composition. Moisture and ash contents were measured using AOAC method.

\section{Sensory Analysis}

The samples kept for stability studies were studied for its sensory characteristics. Hedonic ratings were used to evaluate the sensory attributes of the instant soup mix by 7 expert panel members. Color, Flavor, 
Texture and Overall acceptability sensory attributes were considered during the sensory evaluation of soup powder.

\section{Stability Studies}

Microcapsules stability study helped to determine the formula compatibility.The microcapsules were included in instant soup mix at $10 \%$ level and at various temperatures stability was studied. Testing includes storage of the powder under ambient conditions and $50^{\circ} \mathrm{C}$ in an ordinary oven. Also the sample was kept under refrigeration temperatures $\left(4^{\circ} \mathrm{C}\right)$ for 2 weeks which corresponds to stability study for six months (especially for the food products).

\section{Results and discussion}

Microencapsulation of Fish oil

Experiment outputs by using Skim milk powder as a wall material

Table 3 Experiment outputs by using Skim milk powder as a wall material

\begin{tabular}{|l|l|l|l|l|l|}
\hline Run & $\begin{array}{l}\text { Moisture } \\
\text { content }(\%)\end{array}$ & $\begin{array}{l}\text { Encapsulation } \\
\text { efficiency } \mathbf{\%})\end{array}$ & $\begin{array}{l}\text { Entrapment } \\
\text { efficiency }(\boldsymbol{\%})\end{array}$ & $\begin{array}{l}\text { Bulk } \\
\text { density } \\
\left(\mathbf{g m} / \mathbf{c m}^{\mathbf{3}}\right)\end{array}$ & $\begin{array}{l}\text { Peroxide } \\
\text { value } \\
(\mathbf{m e q} / \mathbf{k g})\end{array}$ \\
\hline 1 & 0.354 & 65.69 & 97.35 & 0.4545 & 5.9 \\
\hline 2 & 0.296 & 66.14 & 97.15 & 0.4578 & 5.9 \\
\hline 3 & 0.279 & 68.23 & 93.91 & 0.4596 & 6.0 \\
\hline 4 & 0.315 & 69.96 & 97.63 & 0.4482 & 5.8 \\
\hline 5 & 0.296 & 66.51 & 96.42 & 0.4432 & 6.0 \\
\hline 6 & 0.285 & 65.15 & 92.39 & 0.4616 & 6.1 \\
\hline 7 & 0.378 & 63.87 & 95.41 & 0.4423 & 6.2 \\
\hline 8 & 0.315 & 65.11 & 94.86 & 0.4437 & 6.3 \\
\hline 9 & 0.289 & 63.91 & 91.73 & 0.4463 & 6.2 \\
\hline 10 & 0.359 & 63.46 & 96.86 & 0.4442 & 6.1 \\
\hline 11 & 0.324 & 64.88 & 93.74 & 0.4451 & 6.2 \\
\hline 12 & 0.272 & 64.53 & 90.69 & 0.4472 & 6.4 \\
\hline 13 & 0.418 & 63.62 & 92.68 & 0.4332 & 6.6 \\
\hline 14 & 0.392 & 63.49 & 92.36 & 0.4386 & 6.9 \\
\hline 15 & 0.359 & 64.87 & 91.57 & 0.4412 & 6.9 \\
\hline 16 & 0.408 & 62.23 & 93.91 & 0.4318 & 6.7 \\
\hline 17 & 0.378 & 64.78 & 92.39 & 0.4307 & 6.8 \\
\hline 18 & 0.315 & 63.81 & 90.17 & 0.4286 & 6.9 \\
\hline
\end{tabular}

Table 3 show the Experiment outputs by using Skim milk powder as wall materials. Moisture content of microcapsules was in the range of $0.272-0.418 \%$. As aqueous phase ratio increased, moisture content of capsules increased. Decrease in oil proportion in total solids slightly increased the moisture content of finished product.

Bulk density of generated microcapsules was $0.4286-0.4616 \mathrm{gm} /$. Decrease in aqueous phase content of feed emulsion increased the bulk density of particles. As the oil proportion in total solids decreased, bulk density of capsules decreased.

The entrapment efficiency of produced fish oil microcapsules was found between $90.17 \%$ and $97.63 \%$ for skim milk powder used as a wall material and increased with decrease in proportion of aqueous phase at emulsion formula for the same oil to total solids ratio. A lower aqueous phase content increases the emulsion viscosity, decelerating the internal circulation of liquid inside the atomized droplets and thereby, resulting in a rapid crust formation ${ }^{11}$. 
The peroxide value of fish oil enveloped within capsules was from a minimum value of 5.8 to a maximum value of $6.9 \mathrm{meq} / \mathrm{kg}$ found for skim milk powder wall material. Peroxide value increased with the increasing aqueous phase content and oil proportion in total solids. The higher peroxide value at higher aqueous phase contents could be related to the lower encapsulation efficiency as the aqueous phase content increased. This led to a poorer protection of fish oil from oxidation process. It is worth noting that the unencapsulated oil is much more susceptible to oxidation reaction than the encapsulated counterpart.

\section{Oxidative stability study of microcapsules}

\section{Rancimat graph}

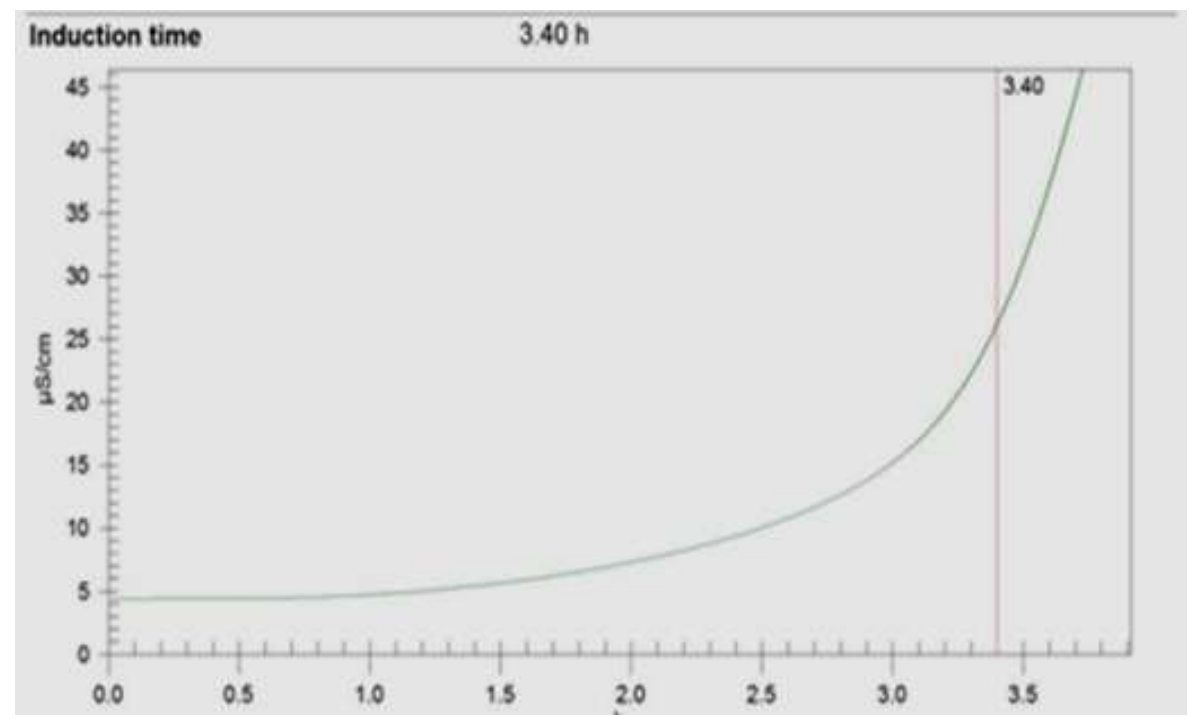

Figure 1: Electrical conductance vs. time graph for the sardine fish oil extracted from microcapsules.

\section{The induction time recorded for the sample was $3.40 \mathrm{~h}$ at $110^{\circ} \mathrm{C}$.}

\section{Powder Particle Size}

\section{Graphical Representation}

Size Distribution by Volume

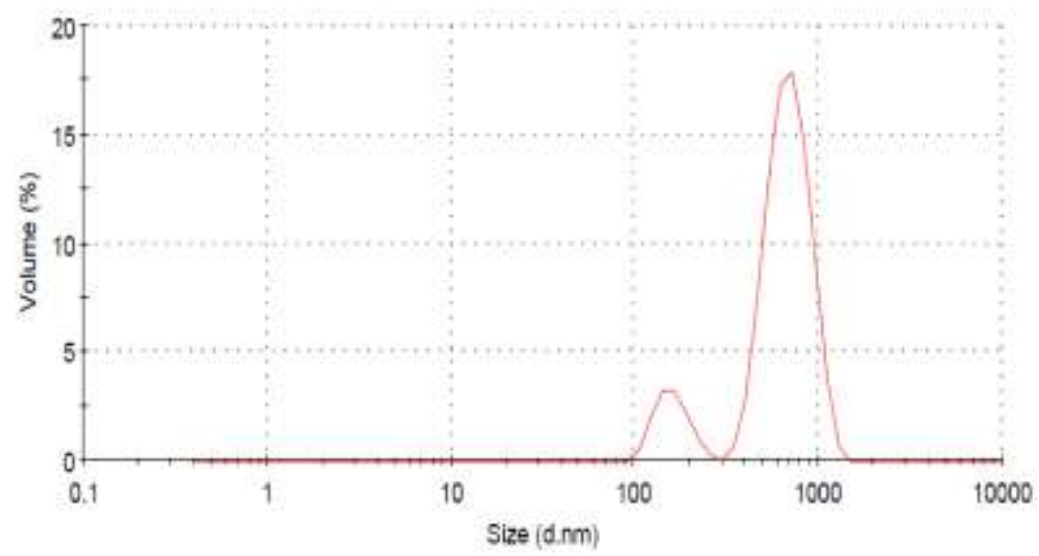

Figure 2: Average particle size of spray dried Fish oil (Skim milk powder as a coating material)

The average diameter of microcapsule was $764 \mathrm{~nm}$ (Figure 2). There were few particles of lower or higher diameter. In 4 sinusoid curve reflects statistical distribution of particle size, which the highest peak reflecting an average particle size. 


\section{Soup powder characterization}

\section{Chemical analysis of soup mix}

Table 4The chemical composition of soup powder

\begin{tabular}{|l|l|}
\hline Parameters & Results \\
\hline Moisture content (\%) & $\mathbf{9 . 4}$ \\
\hline Ash content (\%) & 14 \\
\hline
\end{tabular}

From above result it is observed that by using skim milk powder as a wall material we got finished product of low moisture content, low peroxide value and high encapsulation and entrapment efficiency.Therefore dried microcapsule of Fish oil + skim milk powder emulsion used for application part for better stability of product.

Table 2 showed that among the three formulations Formulation No-2 (mix 2) was taken for analysis for its moisture and ash contents. The resultsare presented in Table 4. The moisture content and ash content in instant fish soup mix was $9.4 \%$ and $14 \%$ respectively. The higher concentration of nutrients in the dried product was due to lower moisture content.

\section{Sensory Evaluation of Soup Mixture}

Sensory evaluation of instant fish soup mix, the mean scores for color, texture, flavor and overall acceptability of three different amount of fish powder in soup powder are presented in Table 5.

Table 5 Means of sensory evaluation of instant fish soup mixes.

\begin{tabular}{|l|l|l|l|l|}
\hline Sample no & \multicolumn{4}{|l|}{ Sensory attribute } \\
\hline & Color & Flavor & Texture & Overall acceptability \\
\hline 01 & 7.57 & 6.71 & 7.86 & 6.71 \\
\hline 02 & 7.71 & 7.86 & 8.43 & 8.00 \\
\hline 03 & 7.43 & 6.29 & 7.43 & 6.57 \\
\hline
\end{tabular}

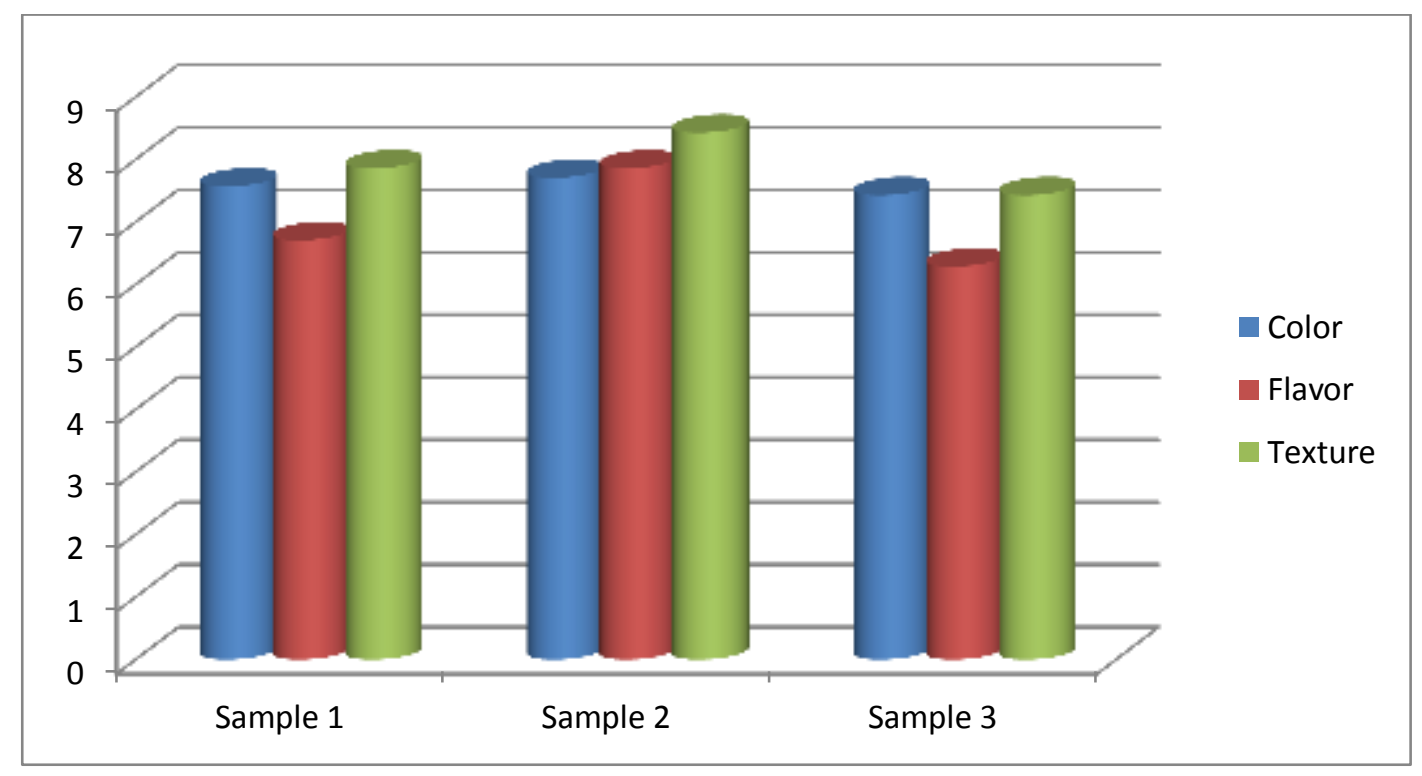

Figure 3:Sensory evaluation chart of instant fish soup mixes

From table 2 results found that in all respects sample- 2 with $10 \%$ spray dried fish powder secured the highest scores and can be ranked as "like very much". Sample with $5 \%$ spray dried fish powder secured the 
second highest score for all quality factors and can be ranked as 'like moderately'. Sample-3 with $15 \%$ spray dried fish powder secured the lowest score among the samples for all quality factors and can be ranked as 'like moderately'.

All the products were equally acceptable with respect to color but were found different from one another with respect to flavor and texture. Thus flavor and texture were over riding factors influencing overall acceptability.

\section{Stability Studies}

Table 6 Stability study of instant soup mix at different temperature conditions

\begin{tabular}{|l|l|l|l|}
\hline Week & $\begin{array}{l}\text { Peroxide value at } \mathbf{4}^{\circ} \mathbf{C} \\
(\mathbf{m e q} / \mathbf{k g})\end{array}$ & $\begin{array}{l}\text { Peroxide value at room } \\
\text { temperature (meq/kg) }\end{array}$ & $\begin{array}{l}\text { Peroxide value at } \mathbf{5 0}^{\circ} \mathbf{C} \\
(\mathbf{m e q} / \mathbf{k g})\end{array}$ \\
\hline 1 & 8.7 & 8.9 & 9.6 \\
\hline 2 & 9.3 & 9.5 & 10.3 \\
\hline
\end{tabular}

Table 6 shows the stability study of instant soup mix. It also shows the storage period for the instant soup mix. From table it was concluded that at $4^{\circ} \mathrm{C}$ we got lower peroxide value as compared to other two storage temperature conditions. At $50^{\circ} \mathrm{C}$ we got peroxide value $10.3 \mathrm{meq} / \mathrm{kg}$ after 2 weeks which is acceptable value for food products. It also shows minimum storage period of instant soup mix for 6 months.

\section{Conclusion:}

For microencapsulation process, skim milk powder used as wall material and sardine fish oil used as a core material. It is found that skim milk powder is effective as a wall materialfor entrapment efficiency, moisture content and peroxide value. Aqueous phase content and oil proportion in total solids of emulsion formula was found to be the most significant variables. The average diameter of microcapsule was $764 \mathrm{~nm}$. That means fish oil dried powder produced using spray dryer are within micrometer range.

Optimal process conditions calculated for the encapsulation processing by spray drying includes: Inlet temperature: $170 \pm 5^{\circ} \mathrm{C}$, Outlet temperature: $90 \pm 5^{\circ} \mathrm{C}$, carrier material concentration as $30 \%$ of aq. phase content and oil loading as $10 \%$ of total solid content and yield obtained about $65-70 \%$.

The data obtained in this research could be useful to scale up the process. Microencapsulated fish oil with Skim milk powder may be beneficial for different food products.

\section{References}

1. Medina, I., González, M. J., Pazos, M., Della Medaglia, D., Sacchi, R., \& Gallardo, J. M. (2003). Activity of plant extracts for preserving functional food containing n-3-PUFA. European Food Research and Technology, 217(4), 301-307. doi:10.1007/s00217-003-0745-9.

2. Wang, C., Harris, W., Chung, M., Lichtenstein, A. H., Balk, E. M., Kupelnick, B., . ., \& Lau, J. (2006). n-3 Fatty acids from fish or fish-oil supplements, but not alpha-linolenic acid, benefit cardiovascular disease outcomes in primary- and secondary-prevention studies: a systematic review. The American Journal of Clinical Nutrition, 84(1), 5-17. doi:10.1093/ajen/84.1.5.

3. Cleland, L., James, M., \& Proudman, S. (2006). Fish oil: What the prescriber needs to know. Arthritis Research \& Therapy, 8(1), 202. doi:10.1186/ar1876.

4. Fakir, A., Gadhave, A., \& Waghmare, J. (2015). A review on a microencapsulation of fish oil to improve oxidative stability. Asian Journal of Science and Technology, 6(3), 1197-1204.

5. Boran, G., Karacam, H., \& Boran, M. (2006). Changes in the quality of fish oils due to storage temperature and time. Food Chemistry, 98(4), 693-698. doi:10.1016/j.foodchem.2005.06.041. 
6. Gharsallaoui, A., Roudaut, G., Chambin, O., Voilley, A., \& Saurel, R. (2007). Applications of spraydrying in microencapsulation of food ingredients: An overview. Food Research International, 40(9), 1107-1121. doi:10.1016/j.foodres.2007.07.004.

7. Jackson, L. S., \& Lee, K. (1991). Microencapsulation and the food industry. Lebensmittel-Wissenschaft + Technologie, 24, 289-297.

8. Shaikh, J., Bhosale, R., \& Singhal, R. (2006). Microencapsulation of black pepper oleoresin. Food Chemistry, 94(1), 105-110. doi:10.1016/j.foodchem.2004.10.056.

9. AOAC. Official Methods of Analysis of Association of Official. Analytical Chemists, 15th Ed. AOAC, Washington, DC.1990.

10. Bligh, E., \& Dyer, W. (1959). Rapid method of total lipid extraction and purification. Canadian Journal of Biochemistry and Physiology, 37(1), 911-917. doi:10.1139/y59-099.

11. Gutcho, M. M. (Ed.). Microcapsules and microencapsulation Techniques. Noyes Data Co.,NewJercy, USA.1976. 